\title{
A Mycobacterium tuberculosis operon encoding ESAT-6 and a novel low-molecular- mass culture filtrate protein (CFP-10)
}

\author{
François-Xavier Berthet, ${ }^{1}+$ Peter Birk Rasmussen, ${ }^{2}$ Ida Rosenkrands, ${ }^{2}$ \\ Peter Andersen ${ }^{2}$ and Brigitte Gicquel'
}

Author for correspondence: François-Xavier Berthet. Tel: +32 26568593 . Fax: +32 26568113. e-mail: berthet@sbbio.be

1 Unité de Génétique Mycobactérienne, Institut Pasteur, 25 rue du $\mathrm{Dr}$ Roux, 75724 Paris cedex 15 , France

2 Department of Tuberculosis Immunology, Statens Seruminstitut, 5 Artilleri vej, DK 2300 Copenhagen S, Denmark

\begin{abstract}
The early secreted antigenic target $6 \mathrm{kDa}$ protein (ESAT-6) is a potent T-cell protein antigen synthesized by Mycobacterium tuberculosis. Its corresponding gene (esat-6) is located in RD1, a 10 kb DNA region deleted in the attenuated tuberculosis vaccine strain Mycobacterium bovis BCG. The promoter region of $M$. tuberculosis esat- 6 was cloned and characterized. A new gene, designated Ihp and cotranscribed with esat-6, was identified. Moreover, computer searches in the $M$. tuberculosis genome identified 13 genes related to the Ihp/esat-6 operon, defining a novel gene family. The transcription initiation sites of the Ihp/esat- 6 operon were mapped using $M$. tuberculosis RNA. The corresponding promoter signals were not recognized in Mycobacterium smegmatis, in which transcription of Ihplesat-6 is initiated at different locations. The $M$. tuberculosis Ihp gene product was identified as CFP-10, a lowmolecular-mass protein found in the short-term culture filtrate. These results show that the genes encoding CFP-10 and ESAT-6 are transcribed together in $M$. tuberculosis and that both code for small exported proteins.
\end{abstract}

Keywords: tuberculosis, Mycobacterium tuberculosis, operon, ESAT-6, CFP-10

\section{INTRODUCTION}

Tuberculosis is an infectious disease that causes the death of three million people each year. Three closely related mycobacteria, namely Mycobacterium tuberculosis, Mycobacterium bovis and Mycobacterium africanum, have been recognized as the aetiological agents of the disease in humans. The virulence of these pathogens is associated with their ability to parasitize and survive within phagocytic cells (Fenton \& Vermeulen, 1996). Little is known about mechanisms governing mycobacterial gene expression during the intracellular growth stage. This issue is of prime importance as the intracellular stage of pathogenic mycobacteria can be viewed as an adaptative process, involving transcriptional regulatory mechanisms.

Mycobacterial genes affecting intracellular growth and

+Present address: Bacterial Antigen Discovery group, SmithKline Beecham Biologicals, Rue de L'institut, 89, B-1330 Rixensart, Belgium

Abbreviation: ST-CF, short-term culture filtrate.

The GenBank accession number for the sequence reported in this paper is AF004671. virulence are being actively sought (Collins et al., 1995; Collins, 1996; Quinn et al., 1996). An important contribution was recently provided by the molecular analysis of the genetic differences between virulent $M$. bovis and the attenuated vaccine strain $M$. bovis BCG. Using subtractive genomic hybridization, Maheiras et al. (1996) identified three regions of difference designated RD1-RD3. RD1 was detected in all strains of $M$. tuberculosis and M. bovis tested but is absent in all BCG substrains.

The esat- 6 gene (Sørensen et al., 1995), encoding the early secreted antigenic target $6 \mathrm{kDa}$ protein (ESAT-6), is found within RD1 where it was provisionally referred to as orf1C (Maheiras et al., 1996). The ESAT-6 protein is a major T-cell antigen which has been purified from M. tuberculosis short-term culture filtrates (ST-CFs) (Sørensen et al., 1995; Harboe et al., 1996). Purified ESAT -6 stimulates the production of gamma interferon from mice memory immune $\mathrm{T}$ lymphocytes and may contribute to the development of antituberculous immunity (Andersen et al., 1995). No function has yet been ascribed to ESAT-6 but its strong antigenic nature suggests that it is produced during tuberculosis infection. 
As a first step to elucidating the mechanisms controlling ESAT-6 expression and antigenicity, we identified and characterized its promoter region. We found that esat-6 is cotranscribed with $l h p$, a new gene encoding a lowmolecular-mass protein found in the $M$. tuberculosis ST-CF. Moreover, we present data suggesting that correct expression of $\mathrm{lhp} /$ esat-6 in M. tuberculosis may require specific transcription factor(s).

\section{METHODS}

Bacterial strains and plasmids. Escherichia coli $\mathrm{DH} 5 \alpha$-was used as a host for cloning experiments. Mycobacterium smegmatis mc $^{2} 155$ (Snapper et al., 1990), M. bovis BCG strain Pasteur 1173P2 and $M$. tuberculosis H37Rv (type strain; ATCC 27294) were used for characterization of promoter activity. The characteristics of the plasmids used in this study are listed in Table 1.

Media and culture conditions. E. coli was grown in solid or liquid Luria-Bertani (LB) medium as described by Sambrook et al. (1989). Mycobacterial strains were propagated in Middelbrook 7H9 broth (Difco) supplemented with albumindextrose complex (ADC) containing $0.05 \%$ Tween 80 (Sigma). When antibiotic selection was required, kanamycin $\left(20 \mu \mathrm{g}^{-1}\right)$ and ampicillin $\left(100 \mu \mathrm{g} \mathrm{H}^{-1}\right)$ were added to the culture media. All bacterial strains were grown at $37^{\circ} \mathrm{C}$ under agitation. For the determination of $\beta$-galactosidase activity, mycobacterial cultures $(5 \mathrm{ml})$ were grown to an optical density of 1. Mycobacteria were then pelleted by centrifugation, resuspended in $500 \mu \mathrm{l}$ phosphate-buffered saline (PBS; $0.145 \mathrm{M}$ sodium chloride, $0.15 \mathrm{M}$ sodium phosphate, $\mathrm{pH} 7.5$ ) and sonicated three times for $1 \mathrm{~min}$ at $80 \mathrm{~W}$.

DNA manipulations. Plasmid extraction, DNA cloning and restriction analysis were performed according to Sambrook et al. (1989). All the restriction enzymes used were purchased from Boehringer Mannheim. The oligonucleotides used are listed in Table 2. Construction of lac $Z$ fusions was achieved using promoter-probe vectors of the pJEM series (Timm et al., 1994) replicative in both $E$. coli and the mycobacteria. The $1.1 \mathrm{~kb}$ Pst I fragment from pIPX61 was blunted with T4 DNA polymerase and inserted into T4-blunted, SnaBI-digested PJEM13 and pJEM14. This resulted in pIPX15 and pIPX16 respectively. Oligonucleotide pairs OF1 and OB1, and OF1 and $\mathrm{OB} 2$, together with PE-1 and PE-4 were used for PCR amplification from pIPX61. Plasmids pIPX46, pIPX47 and pIPX18 were obtained by insertion of the corresponding Bam HI/Asp718-digested PCR fragments into pJEM13 and pJEM15 (see Table 1). Sequence of plasmid DNA was determined on both strands using a Taq Dye Deoxy Terminator Cycle sequencing kit (Applied Biosystems) in the presence of $10 \%$ DMSO. Sequencing reactions were separated

Table 1. Plasmids used in this study

\begin{tabular}{|c|c|c|}
\hline Plasmids & Characteristics* & Source or reference \\
\hline pBluescript II $\mathrm{KS}(+)$ & Cloning vector, $\mathrm{Ap}^{\mathrm{r}}$ & Stratagene \\
\hline pAA249 & $\begin{array}{l}1.8 \mathrm{~kb} \text { EcoRI/BamHI fragment of } M . \text { tuberculosis H37Rv DNA in pBluescript } \\
\text { II KS }(+) \text {, contains esat }-6, \mathrm{Ap}^{r}\end{array}$ & Sorensen et al. (1995) \\
\hline pIPX61 & $\begin{array}{l}1 \cdot 1 \mathrm{~kb} \text { PstI fragment of } M . \text { tuberculosis H37Rv DNA in pBluescript II KS(+), } \\
\text { contains } l h p \text { and part of esat-6, Ap }\end{array}$ & This study \\
\hline pMCT6 & IPTG-inducible E. coli expression vector derived from pET14b & Novagen \\
\hline pJEM13 & Promoter-probe vector used for creating translational fusions (phase +2 ), $\mathrm{Km}^{\mathrm{r}}$ & Timm et al. (1994) \\
\hline pJEM14 & Promoter-probe vector used for creating translational fusions (phase +3 ), $\mathrm{Km}^{\mathrm{r}}$ & Timm et al. (1994) \\
\hline pJEM15 & Promoter-probe vector used for creating transcriptional fusions, $\mathrm{Km}^{\mathrm{r}}$ & Timm et al. (1994) \\
\hline pIPX15 & $1 \cdot 1 \mathrm{~kb}$ Pst I fragment from pIPX61, blunted and inserted in pJEM13, $\mathrm{Km}^{\mathrm{r}}$ & This study \\
\hline pIPX16 & $1.1 \mathrm{~kb}$ PstI fragment from pIPX61, blunted and inserted in pJEM14, $\mathrm{Km}^{\mathrm{r}}$ & This study \\
\hline pIPX18 & PE1-PE2 PCR fragment cloned in the Bam HI $/ K p n I$ sites of pJEM15, $\mathrm{Km}^{r}$ & This study \\
\hline pIPX46 & OF1-OB1 PCR fragment cloned in the BamHI/KpnI sites of pJEM13, $\mathrm{Km}^{\mathrm{r}}$ & This study \\
\hline pIPX47 & OF1-OB2 PCR fragment cloned in the BamHI/KpnI sites of pJEM13, $\mathrm{Km}^{\mathrm{r}}$ & This study \\
\hline
\end{tabular}

*Ap ${ }^{\mathrm{r}}$, confers resistance to ampicillin; $\mathrm{Km}^{\mathrm{r}}$, confers resistance to kanamycin.

Table 2. Oligonucleotide primers used in this study

\begin{tabular}{|llc|}
\hline Primer & \multicolumn{1}{c|}{ DNA sequence } & Position in plPX61 \\
\hline OF1 & 5' GGGGGGATCCCAGGTGACGTCGTTGTTCAGC 3' & $7-27$ \\
OB1 & 5' GGGGGGTACCACGGTGACGTCGTTGTTCAGC 3' & $1069-1051$ \\
OB2 & 5' GGGGGGTACCAACGGTGACGTCGTTGTTCAGC 3' & $1069-1051$ \\
PE-1 & 5' GGGGGGTACCGGGTGGCCGGGAAGTCTGTTG 3' & $448-426$ \\
PE-4 & 5' GGGGGGATCCCTGCAGCAGGTGACGTCGTTG 3' & $1-21$ \\
E64 & 5' CCCTGCAACGAACCTGCCGTCGACTCCACC 3' & $646-617$ \\
\hline
\end{tabular}


on a DNA Analysis system model 373 (Applied Biosystems) as recommended by the manufacturer. DNA sequences were assembled and processed using Gene Navigator (Applied Biosystems) and DNA strider (CEA) software packages. The BLAST algorithm was used to search protein databases for similarity.

Amino acid sequencing. ST-CF was produced as previously described (Andersen et al., 1991). Briefly, M. tuberculosis $\left(8 \times 10^{6}\right.$ c.f.u. $\left.\mathrm{ml}^{-1}\right)$ was grown in modified Sauton medium (Sauton, 1912) on an orbital shaker for $7 \mathrm{~d}$. The culture supernatants were sterile-filtrated and concentrated on an Amicon YM3 membrane. The CFP-10 protein was purified from ST-CF by preparative SDS-PAGE using the Prepcell system (Bio-Rad). A $1 \mathrm{ml}$ fraction containing $8 \mathrm{mg}$ ST-CF was applied on a matrix of $16 \%$ polyacrylamide and separation was performed under an electrical gradient for $22 \mathrm{~h}$. Fractions $(3 \mathrm{ml})$ were collected and analysed on silver-stained SDSPAGE gels. A pool of fractions containing the CFP-10 protein was concentrated in the presence of $0.1 \%$ SDS in a Centricon3 unit (Amicon) followed by acetone precipitation. The precipitate was redissolved in Tricine SDS-PAGE sample buffer and loaded on a precast $10-20 \%$ Tricine SDS-PAGE gel (Novex). After electrophoresis the gel was blotted to Problott PVDF membrane (Applied Biosystems) by semi-dry electroblotting in $10 \mathrm{mM}$ CAPS, $10 \%$ methanol, $\mathrm{pH} 11$. ST-CF was checked for the presence of heat-shock protein 65 and isocitrate dehydrogenase and levels lower than $1 / 100$ th of their corresponding cytoplasmic amount were detected. The PVDF membrane was stained with $0.1 \%$ Coomassie R-250 in $40 \%$ methanol, $1 \%$ acetic acid, and destained in $50 \%$ methanol. The band of interest was excised and subjected to $\mathrm{N}$-terminal sequence analysis by automated Edman degradation using a Procise 494 sequencer (Applied Biosystems) as described by the manufacturer.

Expression and purification of recombinant CFP-10. The lhp gene was amplified by PCR and cloned into the pMCT6 expression vector digested with $\mathrm{Xmal} / \mathrm{BamHI}$. Recombinant CFP-10 was produced in fusion with a stretch of eight histidines at its $\mathrm{N}$ terminus. Recombinant CFP-10 was purified by metal ion affinity chromatography using the Talon resin (Clontech), in the presence of $8 \mathrm{M}$ urea, as described by the supplier. Fractions were collected and analysed by SDS-PAGE. Fractions containing recombinant CFP-10 were pooled and applied to a $1 \mathrm{ml}$ Resource $Q$ column (Pharmacia), in equilibration buffer (10 mM Tris/ $\mathrm{HCl}, 3 \mathrm{M}$ urea, $\mathrm{pH} 7 \cdot 5)$ and eluted using a linear gradient of sodium chloride $(0-1 \mathrm{M})$. Fractions containing recombinant CFP-10 were pooled and dialysed against $25 \mathrm{mM}$ HEPES $\mathrm{pH} 8.5$, concentrated by dialysis against PEG 20000 and dialysed once again against 25 mM HEPES $\mathrm{pH} 8.5$.

Nucleic acid hybridization. Southern and Northern nucleic acid transfer and colony lifts were performed according to Sambrook et al. (1989). The DNA was immobilized by UV illumination at $365 \mathrm{~nm}$ for $3 \mathrm{~min}$. Membranes were prehybridized at $65^{\circ} \mathrm{C}$ for $2 \mathrm{~h}$ in Rapid-Hyb buffer (Amersham) supplemented with denatured $E$. coli DNA $\left(0.25 \mathrm{mg} \mathrm{ml}^{-1}\right.$; Sigma). The labelled probe $\left(10^{6}\right.$ c.p.m. $\left.\mathrm{ml}^{-1}\right)$ was denatured, added to the membrane and incubated at $65^{\circ} \mathrm{C}$ for $2 \mathrm{~h}$. The membranes were washed under high-stringency conditions three times, each for $10 \mathrm{~min}$ at $65^{\circ} \mathrm{C}$ with $2 \times, 1 \times$ and $0 \cdot 1 \times$ SSC, respectively.

RNA extraction. Erlenmeyer flasks containing $100 \mathrm{ml} 7 \mathrm{H} 9 /$ ADC broth were inoculated $1 / 50(\mathrm{v} / \mathrm{v})$ with a saturated preculture of $M$. tuberculosis Mt103 stored at $4{ }^{\circ} \mathrm{C}$. The cells were harvested between days 5 and 16 and D-cycloserine $(1 \mathrm{mg}$ $\mathrm{ml}^{-1}$ ) was added $12 \mathrm{~h}$ before the extraction. Total RNA were extracted using a method described by Bashyam \& Tyagi (1994). The best yields were obtained when extraction was performed at day 7 and provided about $1 \mu \mathrm{g}$ total RNA (ml culture $)^{-1}$.

Primer extension analysis. The mapping of transcription start sites was performed with the E64 oligonucleotide as described by Berthet et al. (1995). Unphosphorylated E64 primer (15 pmol) was 5 -labelled using T4 polynucleotide kinase (New England Biolabs) in the presence of $\left[\gamma_{-}{ }^{32} \mathrm{P}\right] \mathrm{dATP}$ $(100 \mu \mathrm{Ci} ; 3.7 \mathrm{MBq})$, and unincorporated radioactivity was eliminated on a SEP-PAK C18 column (Waters Millipore). RNA $(10 \mu \mathrm{g})$ and labelled TSM-2 primer $(0 \cdot 1 \mathrm{pmol})$ were mixed in a volume of $7 \mu$ containing $0.05 \mathrm{M}$ Tris $/ \mathrm{HCl} \mathrm{pH} 8.3$ and $0.1 \mathrm{M} \mathrm{KCl}$. The reaction mixture was incubated for $1 \mathrm{~min}$ at $94^{\circ} \mathrm{C}, 10 \mathrm{~min}$ at $65^{\circ} \mathrm{C}$ and $15 \mathrm{~min}$ on ice. The annealing mix was adjusted to $12 \mu \mathrm{l}$ by addition of $1 \mu \mathrm{ldATP}, \mathrm{dGTP}$, dCTP, dTTP mix $(2.5 \mathrm{mM}$ each), $0.5 \mu \mathrm{l}$ (6 U) RNAsin (RNAguar; Pharmacia), $2 \cdot 2 \mu \mathrm{l} 5 \times$ reverse transcriptase buffer (0.25 M Tris $/ \mathrm{HCl} \mathrm{pH} \mathrm{8.3,0.2} \mathrm{M} \mathrm{potassium} \mathrm{chloride,} 0.036 \mathrm{M}$ magnesium acetate, $0.01 \mathrm{M}$ DTT), $0.8 \mu \mathrm{l}$ diethylpyrocarbonate (DEPC)-treated $\mathrm{H}_{2} \mathrm{O}$ and $0.5 \mu \mathrm{l}$ avian myeloblastosis virus reverse transcriptase (Boehringer Mannheim). Reverse transcription was performed for $45 \mathrm{~min}$ at $42^{\circ} \mathrm{C}$ and stopped by addition of $5 \mu \mathrm{l}$ T7 sequencing kit stop buffer. Primer extension mixtures were subjected to electrophoresis in $6 \%$ polyacrylamide gels containing $8 \mathrm{M}$ urea, in comparison with a sequence ladder of the esat-6 gene generated using the E64 oligonucleotide, and analysed by autoradiography.

$\boldsymbol{\beta}$-Galactosidase assay. $\beta$-Galactosidase activity was assayed in sonicated extracts of mycobacteria as described by Timm et al. (1994). Experiments were carried out in triplicate. Activity of $\beta$-galactosidase was calculated by the following formula: 1 unit $=200 \times \mathrm{OD}_{420}(\mathrm{mg} \text { protein })^{-1} \mathrm{~min}^{-1}$. Soluble proteins in bacterial extracts were measured by the Bio-Rad colorimetric assay.

\section{RESULTS AND DISCUSSION}

\section{Genetic organization upstream from the $M$. tuberculosis esat-6 gene}

To isolate the potential promoter region, we cloned the $1 \cdot 1 \mathrm{~kb}$ DNA sequence upstream from the $M$. tuberculosis esat- 6 gene. A 150 bp DNA fragment covering the first half of the esat- 6 gene was obtained by digestion of the plasmid pAA249 with EcoRI/PstI (see Fig. 1). This fragment, referred to as ESA-B, was radioactively labelled and used to probe a cosmid library of $M$. tuberculosis strain H37Rv by colony hybridization. A $1.1 \mathrm{~kb}$ PstI restriction fragment shared by three strongly hybridizing cosmids was transferred to pBluescript II $\mathrm{KS}(+)$ to give pIPX61 (Fig. 1). Double-stranded DNA sequencing revealed perfect nucleotide identity between the $1069 \mathrm{bp}$ insert of pIPX61 and its counterpart in $M$. bovis RD1 (Maheiras et al., 1996). It included a 285 bp ORF preceded by a potential ribosome-binding site (AGAGA) in the same transcriptional orientation as esat-6 (Fig. 2a). This ORF was designated lhp (L45 homologous protein) since its deduced product shared $40 \%$ peptide identity with the M. leprae L 45 seroreactive 

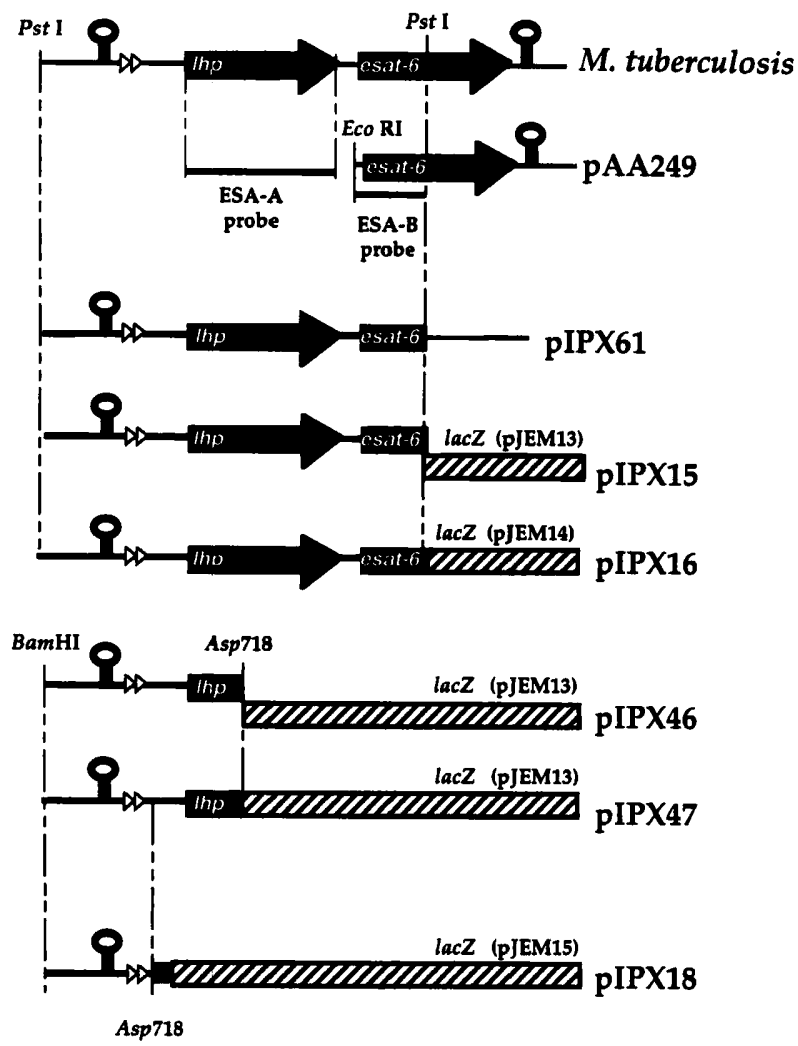

Fig. 1. Plasmid constructs and lacz gene fusions used in this study. Stem-loops represent probable transcription terminators and open triangles indicate $18 \mathrm{bp}$ tandem repeats upstream from lhp. The location of DNA probes (ESA-A and ESA-B) is indicated.

antigen (Fig. 2b). This M. leprae antigen is strongly recognized by sera from lepromatous leprosy patients (Satish et al., 1990). The function of $l h p$ is currently unknown. $l h p$ is absent from the genome of $M$. bovis BCG and was not described in the $M$. bovis RD1 sequence published by Maheiras et al. (1996). However, lh $p$ was recently identified and annotated Rv3874 during the $M$. tuberculosis sequencing project (Cole et al., 1998).

\section{Ihp and esat- 6 define a novel gene family in M. tuberculosis}

Several genes sharing weak similarities with esat-6 have been previously identified during the $M$. tuberculosis genome sequencing project. Although these genes share less than $35 \%$ sequence similarity with each other, they were grouped in the esat- 6 gene family since they all potentially code for small polypeptides of about 100 amino acids (Cole et al.,1998). In that context, we searched the $M$. tuberculosis genome database for the presence of sequences related to the predicted lhp gene product. As reported in Table 3, this allowed us to identify 15 genes potentially coding for proteins related to the $l h p$ gene product and/or to ESAT- 6 . Sequence analysis indicated that $l h p$ and $l h p$-related sequences belong to and extend the esat- 6 gene family identified by Cole et al. (1998). As observed for lhp and esat-6 (Fig. $2 c)$, all these genes are organized in operon-like structures and are frequently preceded by genes encoding repetitive proteins of the PE and the PPE families. The significance of this finding is presently unknown but suggests that gene duplication events have occurred simultaneously for the $l h p /$ esat -6 and PPE/PE gene families.

\section{Ihp encodes the $10 \mathrm{kDa}$ culture filtrate protein CFP-10}

The ESAT- 6 protein consists of 95 amino acids and was previously shown to be present in the M. tuberculosis ST-CF. Since $l h p$ is next to esat-6, and potentially encodes a polypeptide of 100 amino acids, we investigated its eventual presence in the $M$. tuberculosis ST-CF. Low-molecular-mass ST-CF fractions were separated by preparative SDS-PAGE and submitted to systematic $\mathrm{N}$-terminal sequencing. As shown in Fig. 3a, fraction number 4 yielded a peptide sequence matching almost perfectly $(14 / 15)$ the $\mathrm{N}$ terminus deduced from the $M$. tuberculosis lhp gene sequence. This $10 \mathrm{kDa}$ culture filtrate protein was referred to as CFP-10. To further characterize the lhp gene product, we overexpressed and purified recombinant CFP-10 in E. coli, in fusion with a stretch of eight histidines. Separation of recombinant CFP-10 by SDS-PAGE indicated an apparent molecular mass of $14 \mathrm{kDa}$ (Fig. 3b), slightly higher than the apparent molecular mass of recombinant ESAT-6 (His6) (10 kDa). The difference in size between native and recombinant CFP-10 may be attributable to the presence of the histidine tag. Our results demonstrated that $M$. tuberculosis $l h p$ is a gene and encodes a small polypeptide which, like ESAT-6, is found in the low-molecular-mass fraction of the ST-CF. In spite of the fact that no obvious export signal has so far been identified in the sequence of CFP-10, our data suggest this protein is released extracellularly during broth culture of $M$. tuberculosis, as already observed for ESAT-6. Since CFP-10 shares $40 \%$ sequence identity with the $M$. leprae L45 seroreactive antigen, we tested the reactivity of human tuberculous sera against recombinant CFP-10 in a Western blot assay. Twenty human sera were tested against both recombinant CFP-10 and recombinant Des, a potent $M$. tuberculosis humoral antigen (Jackson et al., 1997). Although 20/20 sera reacted against Des, only $1 / 20$ recognized CFP- 10 . This result indicates that CFP-10 may not be a major target of the humoral immune response during human tuberculosis.

\section{Analysis of /hp::lacz and esat-6:: lacZ gene fusions}

To investigate promoter activity, we constructed translational fusions between esat-6, lhp and the lacZ reporter gene. DNA fragments containing either $l h p$ and esat-6 or $l \mathrm{hp}$ alone were inserted into promoter-probe vectors of the pJEM series (Timm et al., 1995), out- or in-frame with regard to lacZ. The resulting plasmids, named pIPX15 and pIPX16, and pIPX46 and pIPX47 
(a)

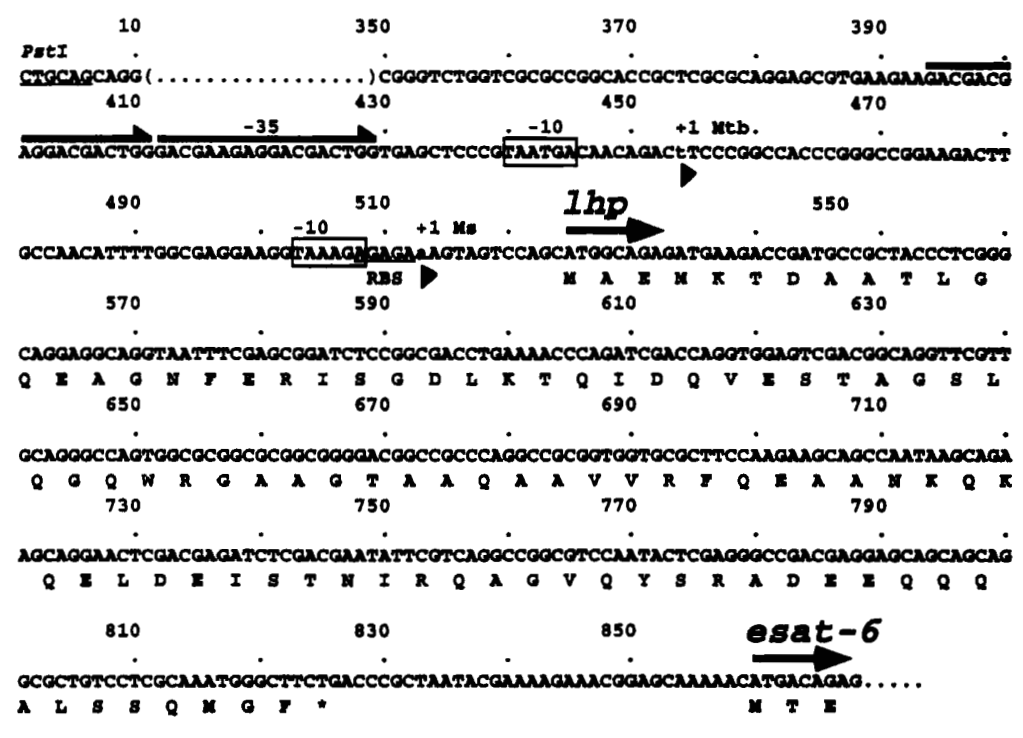

(b)

Mtb CFP-10 MAEMKTDAATLGQEAGNFERISGDLKTQIDQVESTAGSLQGQWRGAAGTA ||||$|:||| ..|:|: .|:.| .::|.::=|:|.:|:.|||| ..|:$.

Mlep L45 MAEMITEAAILTQQAAQFDQIASGLSQERNFVDSIGQSFQNTWEGQAASA

Mtb CFP-10 AQAAVVRFQEAANKQKQELDEISTNIRQAGVQYSRADEEQQQALSSQMGF Mlep L45 ALGALGRFDEAMQDQIRQLESIVDKLNRSGGNYTKTDDEANQLLSSKMNF

(c)

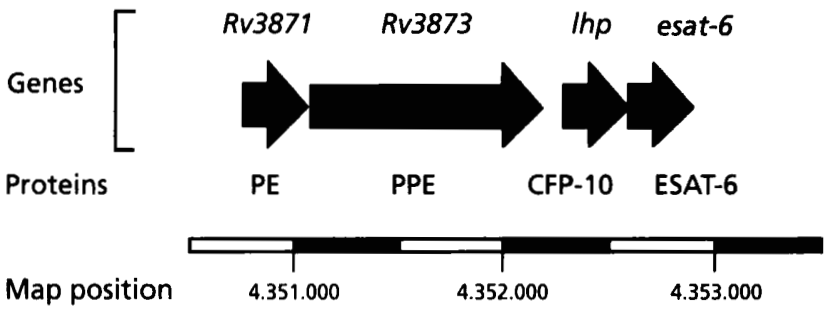

\begin{abstract}
Fig. 2. Gene arrangement upstream from the $M$. tuberculosis esat-6 gene. (a) Nucleotide sequence and deduced amino acid sequence of $\mathrm{hhp}$. A potential ribosomebinding site (RBS) upstream from the predicted start codon is underlined. Potential transcriptional start sites identified in $M$. tuberculosis $(+1 \mathrm{Mtb})$ and in $M$. smegmatis $(+1 \mathrm{Ms})$ are indicated by triangles and deduced -10 regions are boxed. (b) Peptide sequence similarity between the predicted $M$. tuberculosis $\mathrm{h} p$ gene product (Mtb CFP-10) and the $M$. leprae L45 seroreactive protein antigen (accession number X90946) (Mlep L45). Dots, double dots and vertical lines indicate structurally related, chemically related and identical amino acids, respectively. (c) Genetic organization upstream from the/hp/esat -6 operon.
\end{abstract}

respectively (Fig. 1), were subsequently introduced by electroporation into $M$. smegmatis $\mathrm{mc}^{2} 155, M$. bovis BCG Pasteur and $M$. tuberculosis H37Rv. $\beta$ Galactosidase activity was assayed in corresponding bacterial cell extracts and results are presented in Table 4. For the three mycobacterial species tested, strong $\beta$-galactosidase activities were detected in extracts of cells carrying in-frame fusions with lacZ (pIPX16 and pIPX47) but not in extracts of bacteria carrying out-offrame lac $Z$ constructs (pIPX15 and pIPX46). This demonstrated that (i) $l h p$ was expressed and translated and (ii) there was mycobacterial promoter activity present in the $900 \mathrm{bp}$ upstream from the esat- 6 start codon. The differences in levels of $\beta$-galactosidase activity produced from pIPX16 and pIPX47 may reflect differences in the stability of LacZ fusion proteins or corresponding messenger RNAs. Alternatively, it may be attributable to differences in the efficiency of $l h p$ and esat-6 translation signals. An unusual structure [series of poly (A)] upstream from the esat-6 ATG start codon and overlapping the predicted ribosome-binding site, may potentially lead to an enhanced translation of esat$6::$ lacZ.

\section{Ihp and esat-6 are organized as an operon}

To investigate whether lhp and esat-6 belong to the same transcriptional unit, we performed Northern blotting hybridizations using total RNA extracted from M. tuberculosis. Hybridizations were carried out using radiolabelled DNA probes corresponding to either $l h p$ (ESA-A) or esat-6 (ESA-B) genes. With M. tuberculosis RNA, a single hybridization signal migrating at about $800 \mathrm{bp}$ was detected for both the ESA-A and the ESA-B 
Table 3. The Ihp/esat-6 gene family in $M$. tuberculosis

\begin{tabular}{|c|c|c|c|c|}
\hline Gene name & $\begin{array}{l}\text { Similarity to the } \\
\text { lhp gene product } \\
\text { CFP-10 }(\%)^{*}\end{array}$ & $\begin{array}{l}\text { Similarity to } \\
\text { ESAT-6 }(\%)^{*}\end{array}$ & $\begin{array}{l}\text { Operon-like structure } \\
\text { (accession number) }\end{array}$ & $\begin{array}{c}\text { Genes directly } \\
\text { upstream }\end{array}$ \\
\hline $\begin{array}{l}\mathrm{Rv} 0287 \\
\mathrm{Rv} 0288\end{array}$ & $\begin{array}{l}32 \\
21\end{array}$ & $\left.\begin{array}{l}25 \\
28\end{array}\right\}$ & Yes (AL021930) & $\mathrm{PE} / \mathrm{PPE}$ \\
\hline $\begin{array}{l}\text { Rv1036c } \\
\text { Rv1037c }\end{array}$ & $\begin{array}{l}30 \\
18\end{array}$ & $\begin{array}{l}21 \\
27\end{array}$ & Yes (Z92539) & $\mathrm{PE} / \mathrm{PPE}$ \\
\hline $\begin{array}{l}\text { Rv1792 } \\
\text { Rv1793 }\end{array}$ & $\begin{array}{l}28 \\
21\end{array}$ & $\begin{array}{l}\text { NS } \\
26\end{array}$ & Yes (AL022021) & $\mathrm{PPE} / \mathrm{PE}$ \\
\hline Rv3019c & 19 & 32 & Yes (AL021287) & $\mathrm{PPE} / \mathrm{PE}$ \\
\hline $\begin{array}{l}R v 3444 c \\
R v 3445 c\end{array}$ & $\begin{array}{l}25 \\
27\end{array}$ & $\begin{array}{l}28 \\
26\end{array}$ & Yes (Z95389) & Unknown \\
\hline $\begin{array}{l}\mathrm{Rv} 3874(l \mathrm{lhp}) \\
\operatorname{Rv3875}(\text { esat-6) }\end{array}$ & $\begin{array}{r}100 \\
25\end{array}$ & $\begin{array}{r}25 \\
100\end{array}$ & Yes (AL022120) & $\mathrm{PE} / \mathrm{PPE}$ \\
\hline $\begin{array}{l}\text { Rv3890c } \\
\text { Rv3891c }\end{array}$ & $\begin{array}{l}\text { NS } \\
21\end{array}$ & $\left.\begin{array}{l}27 \\
\text { NS }\end{array}\right\}$ & Yes (Z94121) & $\mathrm{PE} / \mathrm{PPE}$ \\
\hline $\begin{array}{l}\text { Rv3904c } \\
\text { Rv3905c }\end{array}$ & $\begin{array}{l}24 \\
33\end{array}$ & $\left.\begin{array}{l}25 \\
25\end{array}\right\}$ & Yes (Z94121) & Unknown \\
\hline
\end{tabular}

"Determined using the GAP algorithm included in the Genetics Computer Group (GCG) package. NS, Not significant.
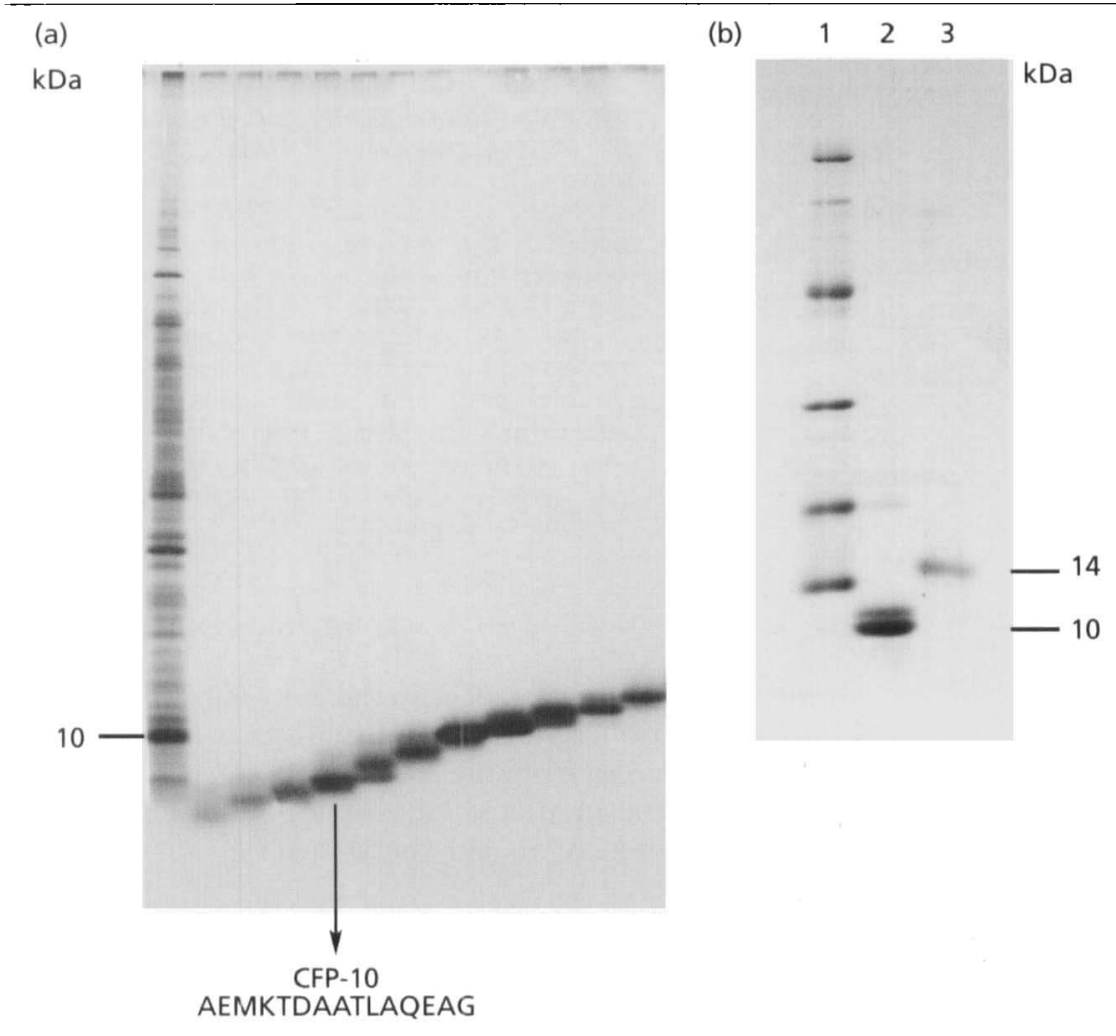

Fig. 3. Detection of $M$. tuberculosis CFP-10. (a) Protein content of the $M$. tuberculosis ST-CF analysed by SDS-PAGE and silver staining (first lane) and corresponding purified low-molecular-mass fractions (following lanes) analysed by SDS-PAGE. Fraction number 4 contained CFP-10, the $\mathrm{N}$ terminal sequence of which is indicated (arrow). (b) Separation of recombinant ESAT-6 and CFP-10 under SDS-PAGE conditions. Lanes: 1, molecular mass markers; 2, recombinant ESAT-6; 3, recombinant CFP-10.

probes (Fig. 4, lanes 2 and 4). The specificity of the ESA$\mathrm{A}$ and ESA-B probes was confirmed by the absence of detectable hybridization with total RNA extracted from M. bovis BCG (Fig. 4, lanes 1 and 3), which lack the $l h p$ and esat- 6 genes. Moreover, comparable amounts of the lhp/esat-6 transcript were detected in early (day 5) and late (day 16) cultures (Fig. 4, lanes 5-8). Consequently, the $l \mathrm{hp} /$ esat- 6 transcript appears to be produced in $M$. tuberculosis from a constitutive promoter and/or is very stable. In view of its size, a mRNA transcript of $800 \mathrm{bp}$ covers both $l h p$ and esat- 6 . The presence of additional genes downstream of esat- 6 is unlikely since a structure 
Table 4. Analysis of $/ h p:: / a c Z$ and esat-6::/acZ gene fusions

\begin{tabular}{|c|c|c|c|}
\hline \multirow[t]{2}{*}{ Fusion with $\operatorname{lac} Z$} & \multicolumn{3}{|c|}{$\begin{array}{l}\beta \text {-Galactosidase activity (units) detected } \\
\text { in sonicated cell extracts of: }\end{array}$} \\
\hline & $\begin{array}{l}\text { M. smegmatis } \\
\mathrm{mc}^{2} 155\end{array}$ & $\begin{array}{l}\text { M. bovis BCG } \\
\text { Pasteur }\end{array}$ & $\begin{array}{l}\text { M. tuberculosis } \\
\text { H37Rv }\end{array}$ \\
\hline $\begin{array}{l}\text { Promoter-less } \\
\text { pJEM15 }\end{array}$ & $58 \pm 10$ & $31 \pm 4$ & $7 \pm 4$ \\
\hline $\begin{array}{l}\text { Out-of-frame } \\
\text { pIPX15 } \\
\text { pIPX } 46\end{array}$ & $\begin{array}{l}85 \pm 21 \\
77 \pm 6\end{array}$ & $\begin{array}{l}17 \pm 3 \\
31 \pm 5\end{array}$ & $\begin{array}{l}31 \pm 6 \\
34 \pm 8\end{array}$ \\
\hline $\begin{array}{l}\text { In-frame } \\
\text { pIPX16 } \\
\text { pIPX47 }\end{array}$ & $\begin{array}{l}1789 \pm 74 \\
1010 \pm 29\end{array}$ & $\begin{array}{l}892 \pm 150 \\
453 \pm 67\end{array}$ & $\begin{array}{l}817 \pm 212 \\
306 \pm 5\end{array}$ \\
\hline $\begin{array}{l}\text { Transcriptional } \\
\text { pIPX18 }\end{array}$ & $36 \pm 4$ & $170 \pm 15$ & $93 \pm 14$ \\
\hline
\end{tabular}

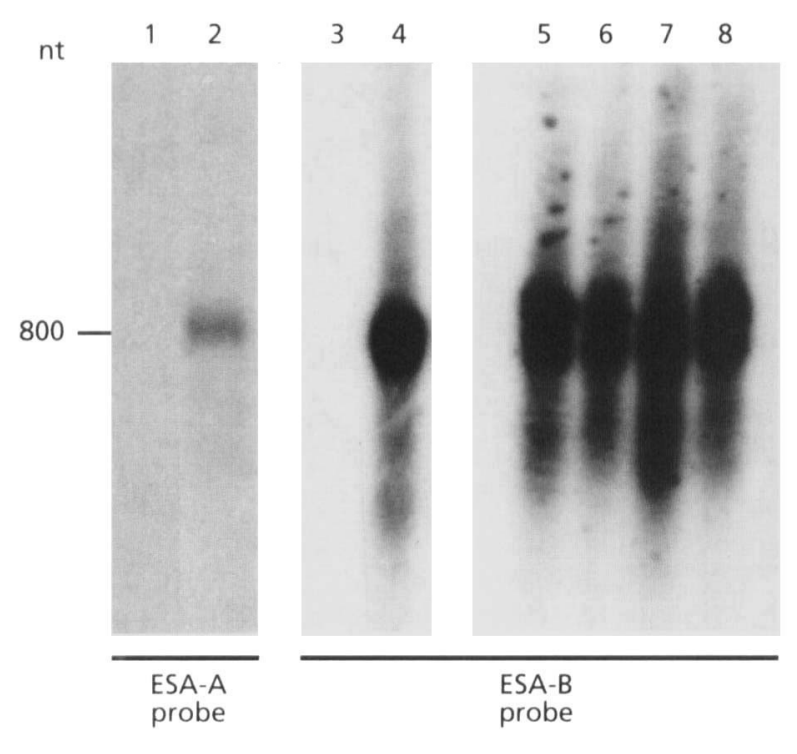

Fig. 4. Analysis of the Ihp/esat-6 mRNA transcript. Total RNA was extracted from $M$. bovis BCG (lanes 1 and 3 ) and $M$. tuberculosis (lanes 2, 4 and 5-8) broth cultures on day 5 (lanes 1-5), day 9 (lane 6), day 13 (lane 7) and day 16 (lane 8). Total RNA $(5 \mu \mathrm{g})$ was separated on $1 \%$ agarose gel supplemented with formamide/formaldehyde and processed for Northern blotting as described by Sambrook et al. (1989). Hybridization was carried out using either the radiolabelled ESA-A (/hp) or ESA-B (esat-6) probes. Autoradiography was performed for 4 (lanes 1 and 2) or 24 (lanes 3-8) h.

similar to a Rho-independent transcription terminator is present $40 \mathrm{bp}$ downstream from the esat-6 stop codon.

\section{Mapping of the /hp/esat-6 promoter activity in M. tuberculosis}

Primer extension experiments were performed to identify the $5^{\prime}$ ends of the $l h p / e s a t-6$ mRNA transcript. Total RNA was extracted from M. tuberculosis and also from M. smegmatis $\mathrm{mc}^{2} 155$ transformed with pIPX16.
By successively walking upstream from the esat-6 start codon, we identified one major and two secondary primer extension products in M. tuberculosis (see Fig. 5a). The corresponding sites in the $M$. tuberculosis genome may correspond to genuine transcription initiation sites. Alternatively, these extension products may result from $5^{\prime}$ end processing of the RNA transcript or transcriptional stops of the reverse transcriptase enzyme used in the assay due to RNA secondary structures. This latter hypothesis is however unlikely since: (i) RNA were extensively denatured by heat before performing primer extension, and (ii) no obvious RNA secondary structures were detected by computer screening. The nucleotides corresponding to primer extension products are close together within a region of $30 \mathrm{bp}$, located about 430 nucleotides upstream from the esat-6 ATG start codon. The position of the mapped $5^{\prime}$ RNA ends identified in $M$. tuberculosis is consistent with an $\mathrm{lhp} /$ esat-6 transcript of about $800 \mathrm{bp}$, as presented in Fig. 4 . The major extension product (T1) is preceded by an $(A+T)$-rich region (TAATGA), which may correspond to the -10 hexamer motif identified in promoters of mycobacteria and other bacterial genera. At the corresponding -35 position, two tandem repeats of a 18 nucleotide motif, extending from positions -25 to -60 , were identified (Fig. 5b). The significance of this organization is unknown but it may serve a regulatory function (Collado-Vides et al., 1991).

\section{The Ihp/esat-6 promoter activity differs in M. smegmatis}

Primer extension mapping using M. smegmatis $\mathrm{mc}^{2} 155$ (pIPX16) RNA yielded signals different from those identified in $M$. tuberculosis (Fig. 5c). The major extension product generated with $M$. smegmatis RNA (S1) corresponded to a nucleotide located immediately downstream from the predicted $l h p$ ribosome-binding site (Fig. 2a). An explanation of this discrepancy may reside in a processing of the $l \mathrm{hp} /$ esat $-6 \mathrm{mRNA}$ transcript 
(a)

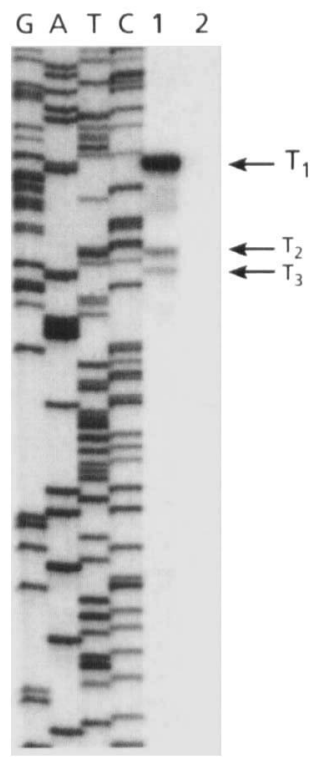

G A T C 12

(b)

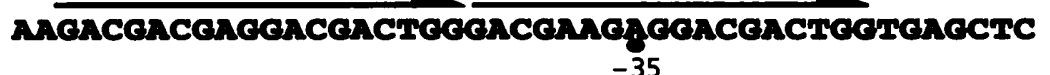

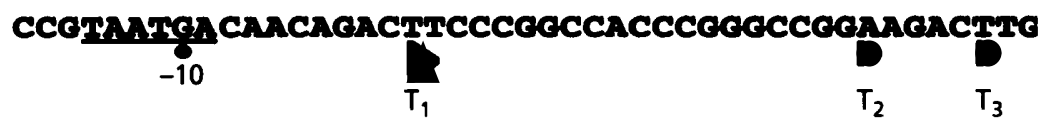

Fig. 5. Mapping of the Ihp/esat-6 promoter activity. (a) Primer extension mapping of the transcriptional start sites ( $T 1, T 2$ and $T 3$ ) in $M$. tuberculosis. Reverse transcription was performed as described by Berthet et al. (1995) using the E64 oligonucleotide with (lane 1) or without (lane 2) RNA. The DNA ladder was generated by sequencing pIPX61 with E64 using the $\mathrm{T7}$ sequencing kit (Pharmacia Biotech). (b) Structural features of the $M$. tuberculosis esat-6 promoter. (c) Primer extension mapping of the transcriptional start sites (S1 and S2) in $M$. smegmatis transformed with pIPX16. Experimental conditions were the same as described in (a). occurring in M. smegmatis. Alternatively, our observation may suggest that the genuine $l \mathrm{hp} /$ esat 6 promoter may not be recognized and that alternative transcription signals are used in M. smegmatis. To test this hypothesis, we constructed a transcriptional fusion with $l a c Z$ encompassing only the promoter region deduced from primer extension mapping in $M$. tuberculosis. The resulting plasmid (pIPX18) was electroporated into $M$. smegmatis $\mathrm{mc}^{2} 155, M$. bovis BCG Pasteur and $M$. tuberculosis $\mathrm{H} 37 \mathrm{Rv}$ and $\beta$-galactosidase activity was assayed. As reported in Table $4, \beta$-galactosidase activity was detected in $M$. bovis BCG and M. tuberculosis protein extracts but not in the protein extract corresponding to $M$. smegmatis containing the pIPX18 fusion. The level of $\beta$-galactosidase activity corresponding to the pIPX18 construct was however five to eight times weaker than the one conferred by pIPX 16 or pIPX47 in M. bovis BCG and M. tuberculosis. In this respect, the lack of a $5^{\prime}$ RNA leader region in the pIPX18 construct may impair the stability of the lac $Z$ transcript, leading consequently to an apparent decrease in the corresponding $\beta$-galactosidase activity. All together, these data suggest that correct expression of the $M$. tuberculosis lhp/esat-6 operon may require factor(s) absent from or not functional in M. smegmatis.

\section{Concluding remarks}

In this study we mapped and characterized the promoter region controlling the synthesis of the $M$. tuberculosis
ESAT-6 antigen. Moreover, we obtained evidence showing that esat-6 is cotranscribed with a novel gene designated $l h p$. The predicted $l h p$ gene product shares sequence similarities with a protein antigen recognized by sera from lepromatous leprosy patients. However, recombinant CFP-10 produced in E. coli does not seem to be a major target of the humoral immune response during human tuberculosis. In this work, we have shown that like ESAT-6, CFP-10 is secreted in the ST-CF. Whether the $M$. tuberculosis CFP-10 protein is, as observed for ESAT-6, a target of the cellular immune response during tuberculosis remains now to be determined.

ESAT- 6 and CFP-10 share the same messenger RNA transcript, have similar molecular masses and are both detected in the extracellular medium during broth culture of M. tuberculosis. This suggests that CFP-10 and ESAT- 6 may interact with one another and/or serve a common function in $M$. tuberculosis. This process may not be essential for growth under axenic conditions since $l h p$ and esat-6 are deleted in M. bovis BCG. Alternatively, other members of the $l h p / e s a t-6$ family may complement the loss of $l \mathrm{hp}$ and esat- 6 in M. bovis BCG. The contribution of lhp and esat-6 to the intracellular multiplication and the virulence of $M$. tuberculosis will now be studied by means of allelic exchange, gene disruption and complementation.

The repetitive structure of the potential ' -35 ' promoter region determined in $M$. tuberculosis has not been 
reported in other mycobacterial promoters characterized so far (Kremer et al., 1995; Bashyam et al., 1996; Kenney et al., 1996). A computer search through the $M$. tuberculosis DNA genome database failed to identify similar motifs in other locations. Such a promoter organization suggests that transcriptional regulator(s) may control the expression of $l \mathrm{hp} /$ esat-6 in $M$. tuberculosis. Such a regulator should be present in both $M$. tuberculosis and $M$. bovis BCG since the pIPX16 construct confers a similar level of $\beta$-galactosidase in these bacteria. This hypothesis is also consistent with the finding that the M. tuberculosis lhp/esat-6 promoter does not function in the fast-growing strain $M$. smegmatis. The search for proteins interacting specifically with the $l \mathrm{hp} /$ esat-6 promoter region is currently under way. This work opens the way to the study of the role of CFP-10 and possible environmental modulation of $l \mathrm{hp} /$ esat-6 expression during M. tuberculosis infection.

\section{ACKNOWLEDGEMENTS}

We thank Dr A. Bengaard Andersen for providing the plasmid pAA249. We are very grateful to Dr B. Wieles for supplying M. leprae sequence data before release to databases. F.X.B. was the recipient of an 'Agence Nationale de Recherche sur le Sida (ANRS)' doctoral grant and is now supported by a 'Bourse de la Fondation Roux'. This work was supported by NIH grant Al35207 and EEC grants BMH4-CT972167 and BMH4-CT972134.

\section{REFERENCES}

Andersen, P., Askgaard, D., Ljungqvist, L., Bentzon, W. M. \& Heron, I. (1991). T-cell proliferative response to antigens secreted by Mycobacterium tuberculosis. Infect Immun 59, 1558-1563.

Andersen, P., Andersen, Å. B., Sørensen, A. L. \& Nagai, S. (1995). Recall of long-lived immunity to Mycobacterium tuberculosis infection in mice. J Immunol 154, 3359-3372.

Bashyam, M. D. \& Tyagi, A. K. (1994). An efficient and highyielding method for isolation of RNA from mycobacteria. Biotechniques 17, 834-836.

Bashyam, M. D., Kaushal, D., Dasgupta, K. K. \& Tyagi, A. K. (1996). A study of the mycobacterial transcriptional apparatus: identification of novel features in promoter elements. J Bacteriol 178, 4847-4853.

Berthet, F.-X., Rauzier, J., Lim, E. M., Philipp, W., Gicquel, B. \& Portnol, D. (1995). Characterization of the Mycobacterium tuberculosis erp gene encoding a potential cell surface protein with repetitive structures. Microbiology 141, 2123-2130.

Cole, S. T., Brosch, R., Parkhill, J. \& 38 other authors (1998). Deciphering the biology of Mycobacterium tuberculosis from the complete genome sequence. Nature 393, 537-544.

Collado-Vides, J., Magasanik, B. \& Gralla, J. D. (1991). Control site location and transcriptional regulation in Escherichia coli. Microbiol Rev 55, 371-394.
Collins, D. M. (1996). In search of tuberculosis virulence genes. Trends Microbiol 4, 426-430.

Collins, D. M., Kawakami, R. P., De Lisle, G. W., Pascopella, L., Bloom, B. R. \& Jacobs, W., Jr (1995). Mutation of the principal sigma factor causes loss of virulence in a strain of the Mycobacterium tuberculosis complex. Proc Natl Acad Sci USA 92, 8036-8040.

Fenton, M. J. \& Vermeulen, M. W. (1996). Immunopathology of tuberculosis: roles of macrophages and monocytes. Infect Immun 64, 683-690.

Harboe, M., Oettinger, T., Gotten Wiker, H., Rosenkrands, I. \& Andersen, P. (1996). Evidence for occurence of the ESAT-6 protein in Mycobacterium tuberculosis and virulent Mycobacterium bovis and for its absence in Mycobacterium bovis BCG. Infect Immun 64, 16-22.

Jackson, M., Portnoi, D., Catheline, D., Dumail, L., Rauzier, J., Legrand, P. \& Gicquel, B. (1997). Mycobacterium tuberculosis Des protein: an immunodominant target for the humoral response of tuberculous patients. Infect Immun 65, 2883-2889.

Kenney, T. J. \& Churchward, G. (1996). Genetic analysis of the Mycobacterium smegmatis rpsL promoter. J Bacteriol 178, 3564-3571.

Kremer, L., Baulard, A., Estaquier, J., Content, J., Capron, A. \& Locht, C. (1995). Analysis of the Mycobacterium tuberculosis antigen 85A promoter region. J Bacteriol 177, 642-653.

Maheiras, G. G., Sabo, P. J., Hickey, M. J., Devinder, C. S. \& Stover, C. K. (1996). Molecular analysis of genetic differences between Mycobacterium bovis BCG and virulent $M$. bovis. J Bacteriol 178, 1274-1282.

Quinn, F. D., Newmann, G. W. \& King, C. H. (1996). Virulence determinants of Mycobacterium tuberculosis. In Tuberculosis, pp. 131-156. Edited by T. Shinnik. Berlin \& Heidelberg: Springer.

Sambrook, J., Fritsch, E. F. \& Maniatis, T. (1989). Molecular Cloning: a Laboratory Manual, 2nd edn. Cold Spring Harbor, NY: Cold Spring Harbor Laboratory.

Satish, M., Esser, R. E., Tholle, J. E. R. \& Clark-Curtiss, J. E. (1990). Identification and characterization of antigenic determinants of Mycobacterium leprae that react with antibodies in sera of leprosy patients. Infect Immun 58, 1327-1336.

Sauton, B. (1912). Sur la nutrition minerale du bacille tuberculeux. C R Acad Sci 155, 860-861.

Snapper, S. B., Melton, R. E., Mustafa, S., Kieser, T. \& Jacobs, W. R., Jr (1990). Isolation and characterization of efficient plasmid transformation mutants of Mycobacterium smegmatis. Mol Microbiol 4, 1911-1919.

Sørensen, A. L., Nagai, S., Houen, G., Andersen, P. \& Andersen, A. B. (1995). Purification and characterization of a low-molecularmass $\mathrm{T}$-cell antigen secreted by Mycobacterium tuberculosis. Infect Immun 63, 1710-1717.

Timm, J., Lim, E. M. \& Gicquel, B. (1994). Escherichia colimycobacteria shuttle vectors for operon and gene fusions to $l a c Z$ : the pJEM series. J Bacteriol 176, 6749-6753.

Received 27 April 1998; revised 3 July 1998; accepted 31 July 1998. 